\title{
science
}
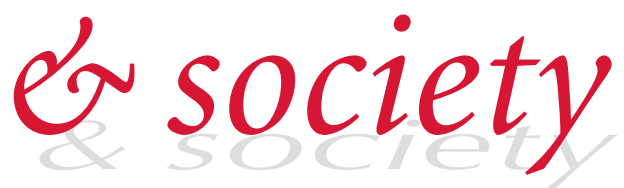

\section{Global warming}

\author{
The good, the bad, the ugly and the efficient
}

\section{Thomas Gale Moore}

G lobal climate change has been portrayed largely as an unmitigated catastrophe for humans and the environment but, in reality, the topic is more nuanced. Although scientists agree that the climate is changing and many accept that anthropogenic increases in $\mathrm{CO}_{2}$ are to blame, there is actually both good and bad news about global warming-and some ugly news about abatement strategies. The media and the scientific literature pay little attention to the possible benefits for some parts of the world of a warming climate; bad news always attracts more attention. So let us consider these benefits, as well as the costs, before discussing the current strategies that are being used to alleviate global climate change.

\section{...there is actually both good and bad news about global warming — and some ugly news about abatement strategies}

Certainly, the global climate will get warmer, but this, in itself, is not intrinsically bad; we do not necessarily live in the 'best of all possible climates'. The Intergovernmental Panel on Climate Change (IPCC; Geneva, Switzerland) has based its estimates of how much the climate will change on the assumption that economic growth is fuelled by increased energy use, which, in turn, increases the production of greenhouse gases. Accordingly, the models that predict the greatest change in climate are driven by forecasts of rapid worldwide economic growth predominantly fuelled by fossil fuels. Yet some IPCC models, which use more realistic growth rates, predict average temperature increases by the end of this century of $2-3^{\circ} \mathrm{C}$. However, virtually all models predict that the coldest parts of the world-near the polar ice caps-will warm the most, with temperatures likely to increase most during the night and the winter (Gates et al, 1992; Houghton et al, 1992).

A $2-3^{\circ} \mathrm{C}$ increase is, in fact, a rather moderate climate change; by contrast, many of the extreme disaster predictions of projected climate change will take place several hundred years in the future when temperatures have increased much more (Stern, 2006). We have no idea what the world will be like in several centuries. Two hundred years ago, it took weeks to cross the Atlantic; most of the western part of North America was unexplored by Europeans and populated only by hunter-gatherers. For all we know, mankind might have colonized Mars and other planets in 200 years.

A warmer climate, especially during the winter months, would mean a longer growing season in all parts of the world that now experience frost and snow during the winter. Any part of the world above $40^{\circ}$ North will probably enjoy less ice and freezing weather, and a greater number of warmer days in the future. The longer periods of temperate weather coupled with an increased level of $\mathrm{CO}_{2}$ in the atmosphere will cause more plant growthin other words, create a greener planet. There is already evidence of increased plant growth: measurements by the Scripps Institution of Oceanography (La Jolla, CA, USA), at Mauna Loa in Hawaii, have documented both a rise in atmospheric $\mathrm{CO}_{2}-$ from 316 parts per million in 1959 to 377 ppm in 2004-and a more pronounced seasonal pattern (http://cdiac.ornl.gov). In general, levels of $\mathrm{CO}_{2}$ in the atmosphere decrease in the spring because growing plants absorb the gas, finally reaching a low by early autumn. As plant growth ceases in autumn, $\mathrm{CO}_{2}$ levels rebound to a midwinter high. Importantly, the amplitude of this pattern has more than doubled since 1958, which suggests that plant growth worldwide has been increasing.

\section{...progress will allow our descendants to deal with almost any difficulties that climate change brings}

A warmer climate will benefit Northern countries particularly (Moore, 1988; Mendelsohn \& Neumann, 2004). It has the potential to reduce the number of seasonrelated deaths, as more people die from the cold in winter than from the heat in summer (NCHS, 1900-1993; Lerchl, 1998; Bentham, 1997). Heating costs will decrease, although this might be partly offset by higher costs for air conditioning in the summer. Less ice and snow in the winter would also mean fewer interruptions to transportation, both on highways and airports. In addition, people tend to prefer warmer climates: most people who retire in the USA do not move to North Dakota or Wisconsin, but head to Arizona or Florida. It also costs more to hire people to carry out the same job in cold areas than in warm areas, reflecting their climatic preferences-for example, salaries in Alaska and Minneapolis are higher than those in Texas (Moore, 1998).

A recent report in The New York Times (New York, NY, USA) about the effect that warmer weather is having in Greenland indicated significant gains for the island: "Winter is coming later and leaving earlier. 

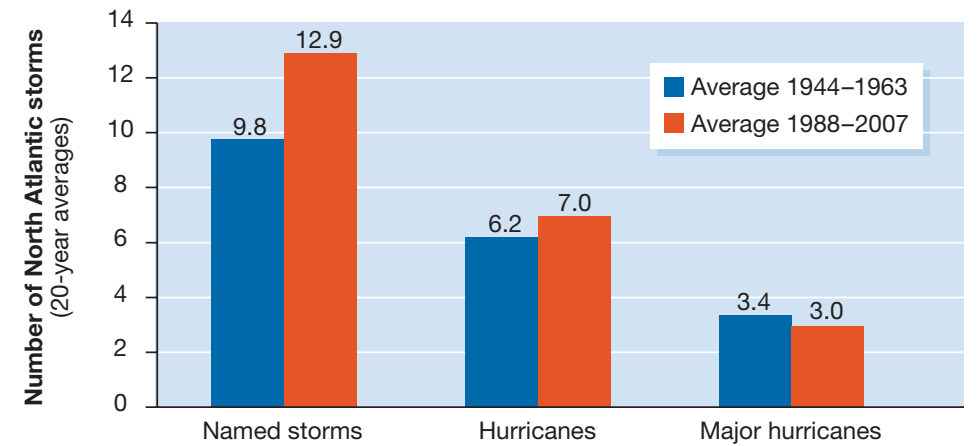

Fig 1 Storms in the North Atlantic (20-year average).

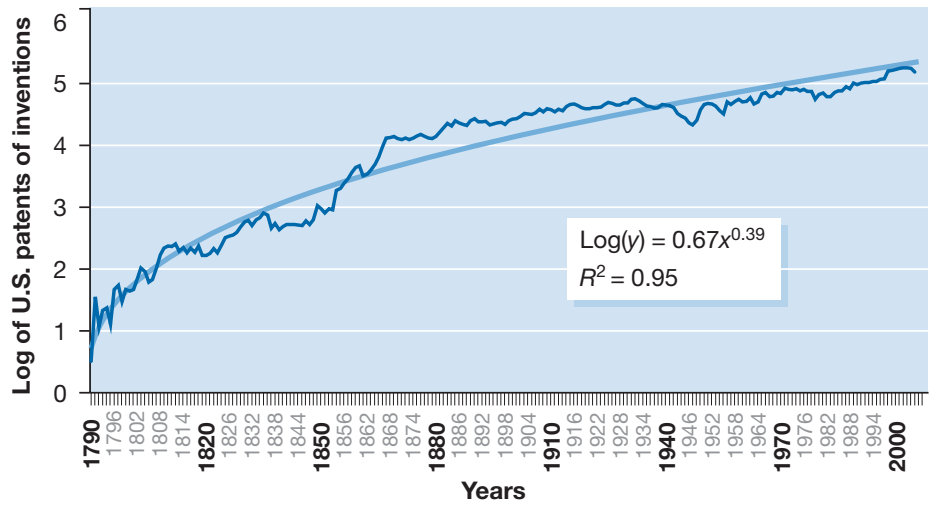

Fig 2 Patented innovations in the USA.

That means there is more time to leave sheep in the mountains, more time to grow crops, more time to work outdoors, more opportunity to travel by boat, since the fjords freeze later and less frequently. [...] Cod, which prefer warmer waters, have started appearing off the coast again. Ewes are having fatter lambs, and more of them every season. The growing season, such as it is, now lasts roughly from mid-May through midSeptember, about three weeks longer than a decade ago" (Lyall, 2007). The article also reported that a Greenland supermarket was stocking locally grown cauliflower, broccoli and cabbage for the first time. The current climatic conditions in Greenland are similar to those during the Medieval Warm Period when Norwegian settlers brought farming to that country and called it Greenland (Lyall, 2007; Moore, 1998).

As the world becomes richer, it becomes better able to deal with significant climate changes...

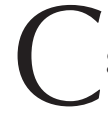
learly, climate change will not be good news for everyone. Rising sea levels will impose significant costs on coastal communities, whereas hotter, dryer weather will affect already arid regions. However, although many worry that a warming climate will bring more, and stronger, storms, the data so far fail to show any increase in hurricanes-especially strong ones-in the Atlantic (Fig 1). Figures from the US National Oceanic and Atmospheric Administration (NOAA; Washington, DC, USA) also indicate that the number of major tornadoes in the USA is declining.

Climate change will also have significant effects on ecological systems and biodiversity, and humans might feel it necessary to mitigate harm or to help these areas to adjust. There will undoubtedly be changes in weather patterns and climate change might bring drier conditions to some areas and increase rainfall in others. It might be necessary to build dams and storage facilities to provide a constant supply of water. In some areas, desalination might also be needed to provide sufficient drinking water. All these adjustments will be expensive. Nevertheless, people living in the temperate or colder regions of the world will experience positive effects that outweigh the costs (Moore, 1988); of course, those not so fortunate must be looked after.

L ven if the pessimists are correct and future climate change reduces food production, wicked storms lash much of the planet, summers are plagued by terrible heat waves, and floods and droughts inundate large areas of the world and reduce the availability of clean water, human beings will be better able to handle such terrible conditions than they are now because technology will advance and people will become richer over the next century. Evidence of an increasing rate of technological advancement comes from patents; the number of patents issued for inventions has continued to rise at an increasing rate since 1790 (Fig 2). Although patented inventions are only a crude measure of technological growth, they do indicate that technology will continue to change the world in which we live. Consider the world 200 years ago when the fastest means of communication was by horseback, or just 100 years ago when telephones were only slowly spreading and radio, much less TV or the internet, were almost undreamed of. Thus progress will allow our descendants to deal with almost any difficulties that climate change brings.

Most observers acknowledge that rich countries are, and will be, better able to withstand environmental changes than poor ones. Whenever there is a major hurricane, typhoon, earthquake, tsunami, flood or drought, it is the poor that suffer the most, whereas the rich can repair and adjust. As the world becomes richer, it becomes better able to deal with significant climate changes, although this wealth must be spread worldwide to have the greatest effect. In the past 50 years, the global per capita income has increased in real terms by about $2 \%$ annually (Fig 3; Jiménez, 2005). If the world continues to grow at that rate during the rest of this century, human beings, on average, will enjoy almost twice the income of the average American today. That is not to say that all people in all countries will be rich, but most will be. Consequently, the world will be more able to deal with any disaster that might befall us from climate change, 
although, of course, the poorest will still need the help of wealthier nations.

However, even if income grows more slowly, at perhaps half of what has been the historical rate, people in the year 2100 will still be much more affluent than they are today. Instead of seeing their incomes increase by over $700 \%$, they will 'only' be $250 \%$ better off. Our great-grandchildren will still be able to afford more tools to deal with any environmental problems.

A Imost all attempts to control or reduce the emission of greenhouse gases have unanticipated consequences and will create large costs. Many of the proposed remedies are also relatively inefficient and would contribute little to reducing emissions. Automobile efficiency standards that let you drive further on less fuel, which are being proposed everywhere, will have only a small effect on overall emissions. Rather, by reducing the cost of driving, they will encourage more driving, which, of course, will partly offset the gains from using less gas per kilometre. A more efficient measure would be to increase the cost of gasoline or, better still, level higher taxes on carbon-based fuels. This would not only encourage the purchase of more efficient vehicles, but also discourage their owners from driving unnecessarily.

\section{Biofuels require farming enormous areas to provide the same amount of power that a nuclear power plant could produce using far less- and far lower quality-land}

The second main initiative intended to offset our reliance on fossil fuels are so-called renewable energy sources. We are already using various energy sources that produce no greenhouse gases such as nuclear, hydroelectric and thermal power, and these, especially nuclear power, could significantly reduce our dependence on coal, oil and natural gas. However, most environmentalists disregard them and often oppose their use. Instead, the environmental lobby have been touting 'renewable energies' such as biofuels, wind power and photovoltaic electricity. Unfortunately, all of these technologies can be more expensive-economically and environmentallyand less efficient than fossil fuels or nuclear

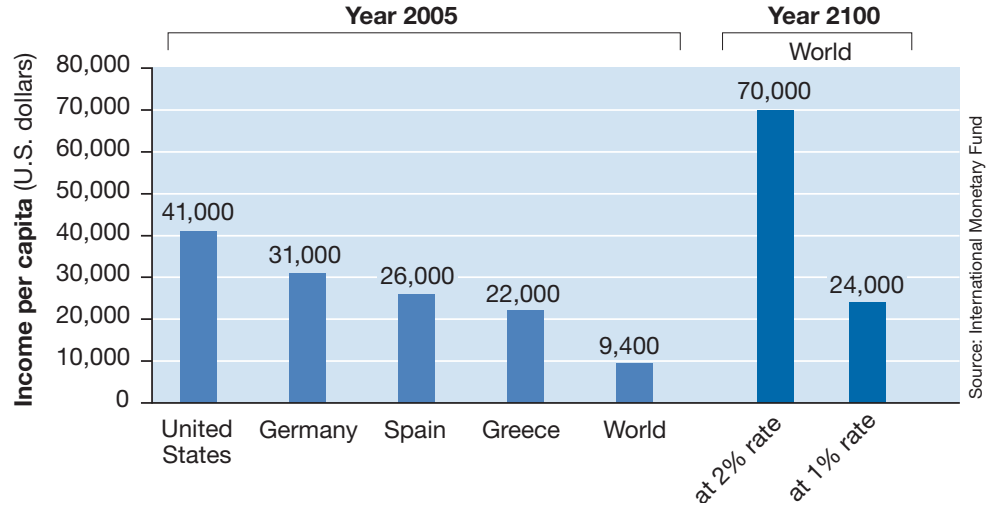

Fig 3 | Growth of global income. Source: International Monetary Fund (Washington, DC, USA).

power. The slight exception might be wind turbines, which have become cheaper to build and have fewer environmental costs. Yet, even under the best circumstances, they are more economically costly than traditional sources of power. In addition, because they are only useful when the wind is blowing not too hard and not too lightly, wind farms must rely on other sources of energy for backup.

Moreover, all these alternative methods of generating power require a huge amount of land (Fig 4), particularly biofuels, which have become popular, especially among farmers. Biofuels require farming enormous areas to provide the same amount of power that a nuclear power plant could produce using far less-and far lower quality-land. In fact, every watt of power that could be generated from biofuels would necessitate 25,000 times as much land as a nuclear power plant would require to produce the equivalent amount of energy (Fig 4). Furthermore, increasing the amount of biofuels has marked side effects for food production. With the development and requirement of the use of ethanol in gasoline, the price of most other agricultural products has increased sharply. Land that was being used to grow corn for animal feed is now being diverted to produce corn for ethanol. Farms that produced wheat or soya beans are shifting to corn production. Moreover, biofuels require both fertilizer

...adopting biofuels might

bring about the further impoverishment of the poor to a greater extent than climate change ever could... and energy to grow the crop, transport it and transform it into a useable fuel. A recent study in Science found that corn-based ethanol actually increased carbon emissions, once the effect on the conversion of forest and grassland to farming is counted in (Searchinger et al, 2008).

ny increase in land use, whether
for growing biofuels or for organic
produce-organic food requires about $20 \%$ more land than commercially farmed food-would mean that land must be diverted either from other farm production or from land that is left fallow, wild or to nature. The production of ethanol has already led to shortages of wheat, soya beans and corn for human and animal consumption. In Mexico and Indonesia, riots have broken out over the escalating costs of corn and soya beans. Biofuels not only increase food prices, but also take land that would have been left to nature and divert it to farming, further reducing the habitat available for many species and contributing to a reduction in biodiversity.

Higher food prices mean little to most of us who live in affluent countries, but they will be devastating for the poor, particularly in many developing countries. Thus, adopting biofuels might bring about the further impoverishment of the poor to a greater extent than climate change ever could, as climate change only has the potential to affect agricultural output gradually over a long period of time. The IPCC scenario that seems most probable, if no steps are taken to reduce greenhouse gases, indicates a temperature rise of about $2-3{ }^{\circ} \mathrm{C}$ by the end of this century, which would mean that the total world agricultural 


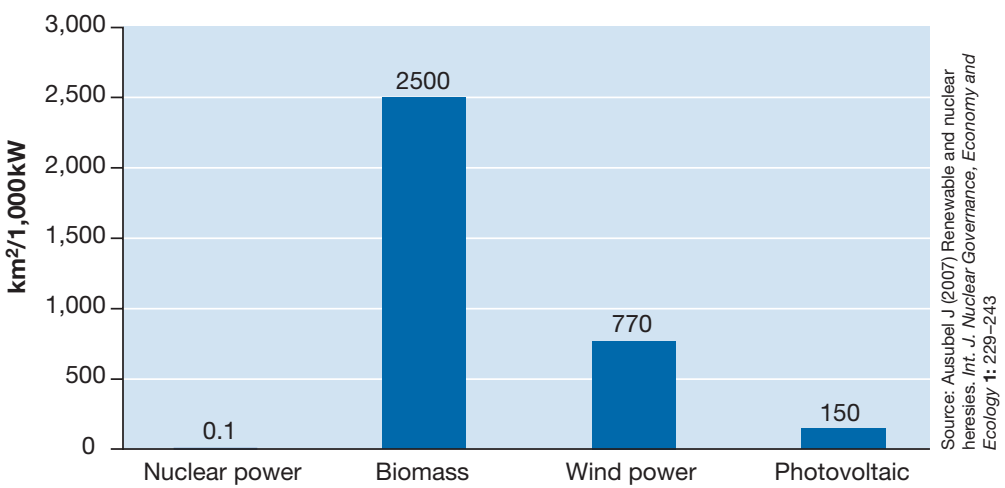

Fig 4 |'Footprint' of various energy sources.

output is either likely to be unaffected by climate change or possibly slightly increased as a result of longer growing seasons and increased $\mathrm{CO}_{2}$. Therefore, using biofuels to decrease greenhouse gas emissions is likely to make things worse for the poor of the world.

\section{Economic growth might be the best protection from the changes that climate change might bring}

Attempting to stabilize greenhouse gases in the atmosphere will bring other costs that have generally been ignored. According to the United Nations' Food and Agriculture Organization (FAO; Rome, Italy), $18 \%$ of greenhouse gases-a larger amount than emissions from transportation-come from livestock (FAO, 2006). Thus, if policy-makers plan to reduce emissions significantly, they must convince the world to become vegan-becoming vegetarian would not be enough.

$\mathrm{S}$ o far, most politicians have advocated a 'cap-and-trade' policy under which businesses and other entities buy or are given emission rights that they can trade. Each country is allocated a certain amount of emission credits to give or sell to their companies. This approach has significant problems that make it inefficient and perhaps even unworkable. As we have already seen in the European Union (EU), the allocations to each country have been too generous, with the result that the price of emission credits has fallen sharply. Some firms have made a lot of money by selling their allocation without doing much to reduce their emissions, and each country in such a system has tried to secure the greatest allocation possible. Enforcement of the cap is therefore a problem, especially in those countries with corrupt governments.

Within the EU, the French Government argues that they produce most of their energy from nuclear power and thus contribute little to greenhouse gas emissions. The French President, Nicholas Sarkozy, worries that costly restrictions imposed on heavy industry will not be sustainable as long as part of the world is exempted from reducing greenhouse gases. He asserts, correctly, that importing the product from an unregulated firm abroad will not reduce and might even increase greenhouse gas emissions. If a country strictly enforces limits on emissions in a crucial industry-for example, steel-then those producers will experience significant costs that might easily lead the executives of the steel firms to move their plants to countries that do not impose such a burden.

\section{The only efficient way to deal with greenhouse gas emissions is to impose a worldwide carbon tax}

However, the EU is now planning to enlarge the European bloc's trading scheme and to reduce emissions further, which might raise costs by $5-48 \%$ and lead to the loss of some of the heavy industry (Bounds, 2008). Governments that agree to restrict emissions will come under severe pressure from both labour and businesses to go easy on their polluters. Bribery, political pressure and foot-dragging will all become common. In the first allocation for the years 2005-2007, generous allocations to power generators resulted in huge windfall profits.

A nother inefficient programme to reduce greenhouse gases are 'green' offsets for emissions; typically, companies offer to plant trees that will absorb $\mathrm{CO}_{2}$ or to take some other steps to reduce greenhouses gases. Although nearly everyone favours trees, it is often impossible or too costly for the purchaser of these carbon offsets to ensure that the trees will be planted. Even if the trees are planted, they must live for decades to absorb the requisite emissions and, in many cases, the trees also require watering and protection against animals and other humans or they might die. Once the tree dies, however, the carbon is eventually released back into the atmosphere, negating the whole programme. Moreover, the amount of carbon that a tree sequesters depends on the species, its age, where it is planted and the climate in which it grows. The cost of monitoring these offset credits will be high and will make this approach expensive.

Although some environmentalists have argued that reducing greenhouse gases by $60-70 \%$ can be achieved at a low cost, in my opinion, this is in fact impossible. Modern industry is based on using large amounts of energy and there are currently no good substitutes for fossil fuels. Nuclear power can produce electricity without emitting greenhouse gases at competitive costs, but it can do little for transportation, food production or deforestation.

Although the evidence suggests that global warming will not significantly harm much of the world in human terms - especially the more advanced countries-some low-lying areas will suffer from rising sea levels and some poor countries might have trouble adjusting to changes in the climate if already arid areas become dryer. The most effective measures to mitigate these severe effects are those that help these countries increase their incomes. Economic growth might be the best protection from the changes that climate change might bring. Whatever is done to mitigate climate change, it must not burden the economy, which would slow growth. For the poor that live in low-lying areas or for those who find that rainfall has become more erratic, help in building dams, dikes and other infrastructure might be appropriate. 
A Ithough rising incomes might be the best solution to the climate change problem, other steps might also be considered necessary. The only efficient way to deal with greenhouse gas emissions is to impose a worldwide carbon tax. This would provide the correct incentive to reduce carbon emissions, but it would generate large sums of money for government officials that would corrupt the process. However, if an international body collected the proceeds and then was mandated to use the money to help advance poorer countries, a lot of good could come out of the effort.

\section{The world should choose the most efficient - that is, the cheapest-way to reduce greenhouse gases because anything else will impoverish much of the world}

From the science at hand it is premature to seriously begin slowing the emission of greenhouse gases. Nonetheless, it might be politically necessary to start curbing emissions. The best plan, therefore, is to impose a modest worldwide carbon tax of, for example, $€ 2$ per ton of carbon, to be administered and collected by an international body. This tax would be imposed in all countries; the amount of the local tax levied would be determined by the exchange rate with the Euro, and the total amount that a country would have to collect would be based on its total emissions. The proceeds of the tax should then be used to help the poorest countries of the world reduce disease and illiteracy. Improvements in the health and education of those in the poorest parts of the world will improve their productivity and consequently economic growth. Securing an agreement from all major countries to impose the tax and remitting the revenue to an international body has obvious difficulties. Nevertheless, the urgency of the problem and the obvious benefits for the poor would make it a goal worth working towards.

A worldwide carbon tax has several important advantages: countries that have already taken steps to reduce their emissions of $\mathrm{CO}_{2}$ such as France and Sweden will not have to pay as much as those that use more fossil fuels. Poorer countries such as China and India will have to pay less per capita than rich countries that burn a lot of coal and gas. No allocation would be needed to determine the emissions quota for any country, nor would it be necessary for any industry or company to lobby for lower restrictions. They would all face the same tax schedule and the amount they pay would depend solely on their emissions. Thus the temptation to bribe, scheme, lobby and plead for favourable allocations would disappear.

Some provision should be made to allow a rebate for steps that absorb or remove greenhouse gases from the atmosphere. Moreover, a modest tax, as suggested here, would be more easily achieved than attempts to establish quotas for different countries, industries and producers. If global warming should become a more significant problem, the tax can be raised. This would be much easier than getting agreement on more stringent quotas.

n conclusion, rich northern countries have little to fear from climate change. It will bring some benefits and some losses but the net effect will be small. If the politicians of the world are unable to agree on how to curb emissions, it will not be a tragedy, at least for the advanced nations. If any progress is to be made on reducing the emissions of greenhouse gases, China, India, Indonesia and Brazil must be included. It might be easier to get them to impose a tax on $\mathrm{CO}_{2}$ and other greenhouse gas emissions than to attempt to specify limits. Many small programmes, such as renewable energies, electric vehicles or imposing mileage standards for new cars and trucks, will not do the job and will impose unnecessary costs on the worldalthough, of course, research into viable alternatives to fossil fuels and their use should be continued. The world should choose the most efficient-that is, the cheapest-way to reduce greenhouse gases because anything else will impoverish much of the world. A carbon tax is the only truly efficient way to deal with the issue.

\section{REFERENCES}

Bentham CG (1997) Health. In Economic Impacts of the Hot Summer and Unusually Warm Year of 1995, JP Plutikof, S Subak, MD Agnew (eds), pp 87-95. London, UK: Department of the Environment

Bounds A (2008) Emissions target threat to EU industry. Financial Times, January 9th

FAO (2006) Livestock's Long Shadow. Environmental Issues and Options. Rome, Italy: Food and Agricultural Organization

Gates WL, Mitchell JFB, Boer GJ, Cubasch U, Meleshiko VP (1992) Climate modelling, climate prediction and model validation. In Climate Change 1992, the Supplementary Report to the IPCC Scientific Assessment, JT Houghton, BA Callander, SK Vareny (eds), pp 97-134. Cambridge, UK: Cambridge University Press

Houghton JT, Callander BA, Vareny SK (1992) Climate Change 1992: The Supplementary Report to the IPCC Scientific Assessment. Cambridge, UK: Cambridge University Press Jiménez V (2005) World Economic Growth Fastest in Nearly Three Decades. Washington, DC, USA: Earth Policy Institute. www.earth-policy.org

Lerchl A (1998) Changes in seasonality of mortality in Germany from 1946 to 1995: the role of temperature. Int / Biometeorol 42: 84-88 Lyall S (2007) Warming revives flora and fauna in Greenland. The New York Times, October 28th Mendelsohn R, Neumann JE (2004) The Impact of Climate Change on the United States Economy. Cambridge, UK: Cambridge University Press

Moore TG (1988) Climate of Fear: Why We Shouldn't Worry About Global Warming. Washington, DC, USA: CATO Institute

Moore TG (1998) Health and amenity effects of global warming. Econ Inq July: 471-488

NCHS (1900-1993) Vital Statistics of the United States. Atlanta, GA, USA: National Centers for Health Statistics. www.cdc.gov/nchs

Searchinger T, Heimlich R, Houghton RA, Dong $F_{\text {, }}$ Elobeid A, Fabiosa J, Tokgoz S, Hayes D, Yu TH (2008) Use of US croplands for biofuels increases greenhouse gases through emissions from landuse change. Science 319: 1238-1240

Stern N (2006) The Economics of Climate Change. London, UK: Her Majesty's Treasury

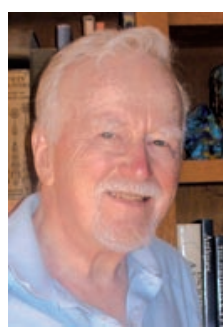

Thomas Gale Moore is a Senior Fellow at the Hoover Institution at Stanford University, Stanford, CA, USA.

E-mail: moore@hoover.stanford.edu doi:10.1038/embor.2008.53 